\title{
O Negro no Rio Grande do Sul: o Vazio Historiográfico
}

Ieda Gutfreind*

É significativo observar a pequena representatividade de estudos sobre o negro no Rio Grande do Sul, principalmente se comparada com outros temas históricos produzidos na época contemporânea por historiadores gaúchos.

A proposta do artigo é refletir sobre essa irrelevante produção, privilegiando um historiador bastante considerado e atuante no período: Moysés Vellinho.

Tal reflexão se torna mais importante ao se reconhecer a presença do negro, desde os tempos coloniais, em terras do Extremo Sul.

Afinal, a Colônia do Sacramento, fundada em 1680, décadas após o término da unificação ibérica (1580-1640), comercializava vários produtos, como couro, tabaco, etc., além do lucrativo comércio de escravos. ${ }^{1}$

Já o sargento-mor Domingos José Marques Fernandes, que veio criar, em 1798, na vila Nossa Senhora Madre de Deus de Porto Alegre, o ofício de Escravidão de Sesmarias, destacava, entre outros assuntos, a importância dos escravos. Sua obra é considerada a primeira história gaúcha e foi publicada em 1804. Ele sugere que:

"Porém a providência que mais que todas e necessária é proibir a entrada da carne salgada dos Espanhóis nos nossos portos da América e a exportação dos escravos para as terras de Espanha. O primeiro mais resulta em gravíssimo prejuízo do comércio da Capitania do Rio Grande; e o segundo é perniciosíssimo a todo

* Professora Adjunto da UFRGS. 
aquele Estado de Portugal; porque este não pode subsistir sem escravos, e por maior que fosse o número deles; nunca deixaria de achar terras incultas, em cujo trabalho se empregassem. E quanto maior é o número de escravos que levam os Espanhóis tanto mais diminuem as nossas forças e aumentam a suas."

Recuando a 1742, em correspondência, José da Silva Paes, considerado o fundador do Rio Grande do Sul pelos historiadores gaúchos, avaliava:

"É terra onde não achei um pobre, e aqueles casais quase todos pela manhã tomam leite, e café custando este aí a 800 rs., e às vezes mais a libra, os queijos podem competir com os do Alemtejo, e em tanta abundancia, que os dão os Lavradores aos Negros em lugar de pão, e estes tem tanta abundância de leite, que o feijão, e abóbora, não o cozem se não em leite."3

Aqui vemos exemplos recuados no tempo, indicadores não apenas da presença mas também da importância do negro no Sul. Sua presença, porém, está em descompasso com a história que se construiu, por que pouco ou nenhum espaço ocupa.

O resgate da história do negro no Rio Grande do Sul é recente, permitindo afirmar que a identidade criada pelos historiadores para 0 gaúcho e o Rio Grande do Sul não apresenta correspondência in totum com a realidade objetiva do processo histórico em si.

Toma-se como referência de estudo a década de 1950. Entre os meses de setembro a dezembro, o jornal Correio do Povo, na sessão "Notas Avulsas", de Carlos Reverbel, lançou uma enquete aos intelectuais gaúchos, indagando acerca das dez obras básicas da bibliografia sul-rio-grandense. Segundo o jornalista, objetivava-se comemorar, com a programação, mais um aniversário da Revolução Farroupilha, assim como indicar um roteiro bibliográfico com os elementos básicos da formação cultural do Rio Grande do Sul, proporcionando aos jovens, recursos para preservarem os valores regionais gaúchos. ${ }^{4}$

Nesta mesma ocasião, Reverbel relembrava as palavras de $\mathrm{Ca}$ pistrano de Abreu sobre o Rio Grande do Sul: 
"Separada a Província Cisplatina, que ficava significando o Rio Grande do Sul? Que se lucra em, derrubadas as muralhas de Ilion, guardar o cavalo de Tróia?"5

Esta opinião do historiador, que consta do prefácio escrito para a obra de Simão Pereira de Sá, História Topográfica e Bélica da Nova Colônia do Sacramento, provocou o orgulho sul-rio-grandense que desde há muito se esforçava em identificar-se como lusitano em sua formação e brasileiro em seus sentimentos, para se assemelhar ao restante do Brasil. Referir-se ao Rio Grande do Sul em situação de igualdade à Província Cisplatina, que se desmembrara do Império no século XIX, sugerir castelhanismos, espanholismos no gaúcho, sempre soaram ofensivos aos intelectuais, os quais nunca deixaram de revidar.

A enquete foi respondida por 47 intelectuais, que indicaram mais de 100 obras, ficando em primeiro lugar o livro de Auguste de Saint-Hilaire, Viagem ao Rio Grande do Sul. ${ }^{6}$

Para os propósitos do artigo, interessa a obra vencedora e que segundo os critérios do concurso, dariam mais recursos aos jovens gaúchos em sua formação. O Diário de Viagem do botânico francês descreve a flora, a fauna, a geografia e a história em seus múltiplos aspectos. Dá-se relevo às sua opiniões acerca dos negros. Proporcionalmente à grande quantidade de dados sobre os indígenas, os informes referentes aos negros são mínimos.

Já nas primeiras páginas do Diário, há referências a um dos acompanhantes de seu grupo de viagem, Manuel, um negro forro, cujas obrigações eram as de campear os animais, limpá-los, carregá-los e descarregá-los. Insatisfeito com seu empregado, Saint-Hilaire reclamava que "Manoel só me fala com ar insolente", 7 além de fazer muitas chacotas com outro membro da comitiva (Firmiano) e dar sempre maus exemplos. ${ }^{8}$ Algumas páginas adiante, o viajante lamenta a decisão de Manuel de abandoná-lo:

"Quanto ao negro Manuel, alugado próximo de Curitiba, e que nenhuma utilidade me tem proporcionado, do qual tenho tolerado com tanta paciência as excessivas susceptibilidades, este achou de deixar-me no justo momento em que podia me prestar algum serviço, 
pois devia conduzir nesta viagem as mulas carregadas de malas."

Observando-se os dados populacionais da Capitania que, segundo Saint-Hilaire, lhes foram fornecidos por José Feliciano Fernandes Pinheiro, então Guarda Alfandegário, havia uma população de 31.000 brancos, 5.399 homens de cor livres, 20.611 homens de cor escravos e 8.655 indígenas. ${ }^{10}$ Tais números, por si só, escrevem a história da imensa maioria da população negra por voltas de 1820, na Capitania.

Saint-Hilaire, homem do seu tempo, está marcado pela preocupação com raças, identificando-as em superiores e inferiores. Negros e índios compõem esta última.

Ainda não se havia chegado à sofisticação das doutrinas racistas de Gobineau; Lapouge e Chamberlain produzirão suas obras no final do século XIX e início do XX. No entanto, durante os séculos XVII e XVIII, o vocábulo raça foi utilizado em larga escala, justificando a superioridade do branco, conquistador de grandes impérios coloniais. Aliás, desde 0 século XVI, o branco europeu realizava estudos para averiguar a existência ou não, de qualidades humanas, em povos conquistados, tanto nos indígenas do continente americano, quanto nos negros africanos.

$O$ viajante francês, respirando o ar do seu tempo, assim se referia ao tratamento dado aos indígenas pelos habitantes da Província sulina:

"Disse [...] que essa gente só fala aos índios com brutalidade, mas isso não é, realmente, entre os portugueses, prova de maldade [...]. Testemunhos perenes da inferioridade dos homens dessa raça, eles acostumam-se a quase confundi-los com os animais, e ninguém será tomado por bárbaro se para ensinar a um cão ou domesticar um cavalo fizer uso do chicote."11

Mais adiante, destaca os "defeitos inerentes à sua raça", ${ }^{12}$ referindo-se a um índio. Com esta mesma concepção, refere-se ao negro, aliás este sem condições inclusive para compor a população:

"[...] razões da calma com que se operam as insurreiçōes neste país, e que, principalmente nesta Capitania, não existe praticamente o que se chama 'populaça', e quando existe é pouco numerosa. Os negros 
que a representam são muito distanciados dos homens livres e por demais subservientes para se meterem nessas cousas." 12

Influenciado pelas idéias racistas e também pelos determinismos, Saint-Hilaire dava muito valor à influência do clima sobre os seres vivos. ${ }^{13}$ Tratava-se de uma teoria em voga desde há muito, bastando lembrar Montesquieu em sua obra $O$ Espírito das Leis, que, na terceira parte, inicia com o capítulo "Das leis em relação com a natureza do clima".

O viajante francês identificava, entre os que denominava de "nossa raça", ou seja, brancos, com alterações raciais e de conduta na América, motivadas pelas diferenças climáticas. Além do fator clima, também enumerava as condições de vida como o viver livre nos campos, os exercícios violentos, a falta de policiamento, o hábito de ver correr sangue e maltratar os animais. ${ }^{14}$ Se este é o quadro que o viajante identificava entre os brancos da sua raça, pouco ou nada restava às demais.

Crítico da miscigenação, acusava a ação nociva da mescla de brancos e índios, ${ }^{15}$ deplorando: "essas misturas farão a capitania do Rio Grande perder a sua maior vantagem - a de possuir uma população sem mescla". ${ }^{16}$

É evidente que, neste quadro, a miscigenação com o negro também era lastimada. Opositor das mestiçagem, captou o papel que o negro exercia nesta sociedade, relatando a reação de um proprietário ao saber que um de seus escravos morrera afogado: "Ah, meu dinheiro! Meu dinheiro! Que me custa tanto a ganhar!" ${ }^{17}$ e acrescenta seu entendimento das lágrimas da mulher deste proprietário, argumentando: "mas a rudeza com a qual trata os escravos faz-me crer que ela não chorava outra cousa senão seu dinheiro". ${ }^{18}$

Esta é, segundo o viajante, a posição do negro na Capitania, ou seja, mão-de-obra para todas as atividades braçais, na busca de água nos poços carregada em barris, ${ }^{19}$ no trabalho nas estâncias, ${ }^{20}$ nos pomares,${ }^{21}$ no corte e transporte da lenha, ${ }^{22}$ na indicação de caminho, ${ }^{23}$ etc.

O negro é sempre visto como cometendo algum mal, seja se suspeitando infundadamente do roubo de um cão, ${ }^{24}$ seja atribuindo péssimas aptidões para o trabalho:

"Os negros são naturalmente pouco ativos; quando livres só trabalham o suficiente para não morrerem de 
fome; quando amedrontados trabalham mal e com excessiva lentidão."25

O negro também recebe valorização negativa, de acordo com os preconceitos de ordem sexual vigentes na época. ${ }^{26}$

Saint-Hilaire, embora negasse ao negro o direito de compor a população por ser subserviente em demasia, contradizia-se ao reconhecer sua valentia, indicando serem contínuas as fugas das estâncias e que:

[...] sendo voz geral que os mais valentes soldados de Artigas são os negros fugidos, o que é natural porque se batem por sua liberdade. Além disso, o negro é mais bravo do que o índio porque possui melhor noção da obra do amanhã, donde sua coragem de tudo sacrificar em busca de um futuro melhor."2s

A freqüência de crimes entre os negros foi destacada, e o viajante a justificava em função da má qualidade do negro que vinha para o Rio Grande do Sul. Segundo ele, eram os imprestáveis e os de má índole do Rio de Janeiro. Complementava que, quando se queria "intimidar um negro, ameaçavam-no de enviá-lo para o Rio Grande". ${ }^{29}$

Saint-Hilaire desfilava em seu Diário diferenças de tratamento, "0 impiedoso sistema" em vigor, mas concordava que "torna-se necessário tratá-los com mais energia", ao se referir aos negros das charqueadas, porque são "em grande número e cheios de vícios, trazidos da capital". Complementava a asserção com uma frase lapidar que, em verdade, é o eixo sobre o qual girou a historiografia sul-rio-grandense contemporânea, quando, brevemente, se referia ao negro: "Entretanto, não há, creio, em todo o Brasil, lugar onde os escravos sejam mais felizes que nesta capitania". 31

A assertiva acima pode ser exemplificada com a produção de Moysés Vellinho, crítico literário, também historiador, que desde a década de 1920 até a de 1970 representou a ideologia dominante entre a maioria dos intelectuais gaúchos.

Em termos genéricos, a preocupação fundamental da historiografia neste período referia-se ao estudo da formação histórica do Rio Grande do Sul, seu passado político, no qual se destacavam estudos sobre 
brancos. Em sua grande maioria, os historiadores sul-rio-grandenses, entre os quais Moysés Vellinho, que é um líder, pouca ou nenhuma atenção deram ao estudo do negro. Tomaram como suas as afirmações do viajante francês Auguste de Saint-Hilaire em relação ao negro. Transformaram em matrizes seus dizeres e deles tiraram cópias, desde a diversidade de tratamento do negro desta capitania em relação às demais, seu menor número, a diferença de tratamento que havia nas estâncias e nas charqueadas. Pouca importância deram às sublevações, às fugas, aos motivos que os levaram a cometerem crimes. Não se detiveram no estudo de sua origens, de sua história e da miscigenação que ocorreu.

Algumas obras, capítulos, parágrafos abordaram, talvez menos que isto, pois o verdadeiro objetivo da historiografia contemporânea gaúcha foi substantivar uma história sul-rio-grandense desde o início vinculada a Portugal e ao restante do Brasil, excluindo o papel do negro em sua formação. É daí que advém o zelo pela história açoriana, o aprofundamento na busca documental destes laços de origem, o retorno ao passado lusitano, ignorando as íntimas relações com a África Negra.

Apenas recentemente, estudos em profundidade têm sido feitos acerca da história do negro no Rio Grande do Sul.

Referindo-se novamente a Moysés Vellinho, representante de significativa envergadura no campo da historiografia sulina, facilmente se comprova o universo ideológico vigente.

Há dois artigos nos quais Moysés Vellinho desenvolveu sobre o negro, sendo um deles "O negro americano: algumas observações"32 publicado inicialmente na Revista Província de São Pedro, n 18 em 1953. São reflexões acerca do recismo norte-americano, a partir de impressões colhidas em uma viagem aos Estados Unidos, na década de 1950. O contato com negros, seus modus vivendi, as opiniões de intelectuais deixaram-no impressionado, reconhecendo que "o problema do negro nos Estados Unidos é inesgotável nos seus aspectos mesmo para um viajante apressado", ${ }^{33}$ acrescentando em seguida:

“[...] Do alto de nossa democracia racial, infelizmente ainda tão desconfiada de suas virtudes, imaginamos que o homem de cor nos Estados Unidos é uma criatura acuada pela intolerância dos brancos". ${ }^{32}$ 
A tese de Vellinho era de que o negro americano adquiriu consciência de si devido à segregação. Este fator, segregação, foi avaliado por ele como tendo um efeito estimulante e não depressivo.

Premido por ela e pelo exclusivismo branco, o negro reagiu, "cresceu de si mesmo, refugiando-se numa espécie de racismo premonitório", ${ }^{35}$ concluía Vellinho. Refletindo-se sobre a historiografia gaúcha em geral e a produção de Moysés Vellinho em particular, observam-se contradições entre o conteúdo deste texto e o que o conhecimento histórico criou acerca do negro no Rio Grande do Sul.

No outro trabalho, "Gilberto Freyre e a valorização do português"36 publicada na obra Gilberto Freyre: sua ciência, sua folosofia, sua arte. Ensaios sobre o Autor de Casa Grande e Senzala e sua influência na Moderna Cultura do Brasil, em 1962, Vellinho avaliava a obra deste autor como um divisor de águas, afirmando que era necessário aceitar e "proclamar sem vãos constrangimentos a nossa condição de povo mestiço". ${ }^{37}$ Tecia elogios ao autor que redescobriu o Brasil, "fundou uma sociologia de portas abertas, livre de preconceitos, solidamente assentada sobre o princípio da igualdade fundamental das raças e dos povos", ${ }^{38}$ nascida com ânimo de aventura e o "dom de cruzar-se e fraternizar com outros povos sem quaisquer reservas ou discriminações" ${ }^{39}$

Os trechos podem induzir à idéia de que Moysés Vellinho aceitava e defendia a mestiçagem, no entanto, o conteúdo do artigo era justamente valorizar o português, destacar sua superioridade e não o problema da mestiçagem.

Indaga-se como a idéia de democracia racial, explicitada no porimeiro texto, a aceitação da mestiçagem, a defesa do princípio de igualdade fundamental das raças e dos povos no texto seguinte, acomodaram-se na produção historiográfica deste autor? Qual a relação existente entre a visão de Moysés Vellinho sobre o negro em sua historiografia com o que se expôs sobre o negro extraído do Diário de Saint-Hilaire?

Avaliando-se a produção historiográfica de Vellinho, inclusive os editoriais que redigiu para a Revista Província de São Pedro (1945-1957, 21 números), não se constata a preocupação com os temas negro/ escravidão. 
Reconhece-se que Vellinho foi um crítico literário de primeira linha. Dirigiu-se para o campo da história e é neste sentido, na tarefa de historiador, que se pretende destacar.

Na década de 1950, junto com textos de crítica literária, observa-se a preocupação de Vellinho em desenvolver trabalhos, objetivando identificar diferenças entre o Rio Grande do Sul e o Prata: seu referencial é o gaúcho e, entre o gaúcho platino e o sul-rio-grandense, evidenciava distinções.

A década seguinte, 1960, foi seu período mais profícuo. Os temas referentes à história se ampliaram: a expansão jesuítica na área sulina teve contínuos estudos e apresentações públicas, a diferenciação entre o gaúcho platino e o sulino foi mais desenvolvida, alargando-se com estudos sobre o Rio Grande e o Prata. Porém, o que se impõe são os textos do autor sobre a história gaúcha a partir da situação da FRONTEIRA GEOGRÁFICA (também feita pelos demais historiadores gaúchos contemporâneos). Neles, Vellinho destacava o esforço da Coroa Portuguesa e dos "filhos do Rio Grande" em luta permanente contra os invasores espanhóis/castelhanos. Pode-se enumerar uma série de textos, como "A configuração atual do Rio Grande e sua fronteira histórica" ${ }^{40}$ e Capitania d'El Rei, com o subtítulo "Aspectos polêmicos da formação rio-grandense". ${ }^{41}$ Integra este último uma série de ensaios com as preocupações do autor: "A expansão meridional do Brasil", "Os jesuítas", "As missões orientais e seus heróis perante a história do Rio Grande do Sul", "Cristóvan Pereira", "O Rio Grande e o Prata: contrastes" e "A fronteira e a língua". Em 1970, a obra recebeu segunda edição.

A década de 1970 foi ponteada com a obra Fronteira ${ }^{42}$ símbolo final da construção do panteón dos heróis da história sul-riograndense, já iniciado em Capitania d'El Rei. Os temas permaneceram semelhantes, modificaram-se os títulos, acrescentaram-se heróis: "O Continente de São Pedro amanhece" e "Os Pinto Bandeira" exemplificam a afirmação. E o resgate de uma história centrada no espírito de fronteiras.

Questiona-se em que texto, onde discorreu Moysés Vellinho sobre 0 negro? Pouco, quase nada se encontra. A escravidão indígen $a^{43}$ era justificada pela categoria tempo em que ocorreu, o que permite admitir que justificava também a escravidão negra ${ }^{44}$ pelo mesmo elemento. 
Em "Conquista e Povoamento do Rio Grande do Sul", fica evidenciada a tese de Vellinho acerca da elaboração histórica do Rio Grande do Sul: “desde os primórdios até a configuração definitiva forma contingentes humanos do complexo luso-brasileiro que povoaram a área sulina." 45

Nela, enumerava os pioneiros da colonização espontânea e da dirigida, soldados de linha ou milicianos, voluntários de São Paulo e de Santa Catarina, campeadores de Laguna, Santos, planaltos de Curitiba e Piratininga, Rio de Janeiro, Bahia, Minas Gerais, retirantes da Colônia do Sacramento e, de 1732 em diante, os açorianos e reinóis em pequeno número. Estes foram para Vellinho, os legítimos pioneiros, portadores da mesma herança cultural quer "por extração histórica, absorção e contágio". 46

Permanece-se na indagação: e o negro, o índio por extensão, que papel lhes tocava nesta formação histórica? Para Vellinho estes elementos foram brotando dos seus flancos "na surda promiscuidade do mato e da senzala". ${ }^{47}$ Apenas em relação aos aborígenes, vistos como "barro pobre e obscuro", ${ }^{48}$ o historiador desenvolveu um pouco mais, vendo-os como "resíduos desarvorados de hordas primitivas das antigas reduções missioneiras. Do ponto de vista antropológico, tais elementos se apagaram na mistura". ${ }^{49}$

Em Capitania d'El Rei, referia-se à mestiçagem, mas sempre em relação à do índio com o branco. ${ }^{50}$ Quando se referiu à mistura sem dificuldade do açoriano com escravos, negros e índios, foi através da citação de outro autor. Ainda em relação ao negro, afirmava: "Como não podia deixar de ser, também tivemos a incidência do sangue africano". 51

É, em nota de rodapé, referia-se aos dois autores gaúchos que desenvolveram trabalhos sobre o negro. ${ }^{52}$ Ainda em Capitania d'El Rei, em um parágrafo, resumiu a participação secundária dos índios, negros e mestiços para a elaboração do tipo social rio-grandense..$^{53}$

Enfim, a produção historiográfica de Moysés Vellinho destacava, isto sim, "os nossos maiores", 54 "os troncos lusíadas", 55 "nossos avós portugueses", 56 "a cepa cultural", 57 "a pura cepa luso-brasileira", 58 "a velha cepa lusitana". 59

Moysés Vellinho compunha, com outros historiadores, o grupo que defendia (ainda alguns defendem) a afirmação de Pandiá Calógeras: "O 
Rio Grande é a marca do Brasil", aliás, consta como epígrafe em Fronteira.

Seu projeto político-ideológico era a articulação do Rio Grande do Sul com o restante do Brasil. Era esta a proposta de sua historiografia e a de vários outros historiadores contemporâneos.

Merecidamente, Vellinho recebeu o título de "um velho chefe de clã lusitano em terras gaúchas", quando de uma entrevista concedida ao suplemento Caderno de Sábado, do Correio do Povo, em sua homenagem, de $1^{2}$ de setembro de 1979. Ele destacou, nesta entrevista, que, com a fundação da Revista Província de Sāo Pedro, objetivava-se "resguardar nossa cultura e o espírito cultural da raiz lusitana".

Não deixa de ser paradoxal, em um Simpósio sobre o negro e a escravidão, expor-se a inexistência de uma historiografia sobre o assunto, destacando-se um dos mais conceituados historiadores gauchos.

Contudo, através desta ausência, deste espaço em branco, é que se pode aquilatar o universo ideológico que permeava os historiadores gaúchos. Suas preocupações eram político-econômicas, sua ideologia conservadora e elitista, sua proposta, a construção de uma identidade para o Rio Grande do Sul e o gaúcho, acima de tudo lusitana, mesmo que obtusa ou incompleta.

O concurso do negro e do indígena na formação social sul-riograndense teria que aguardar uma outra conjuntura histórica no curso da História sulina. Oxalá, para tanto, estejamos aqui.

\section{Notas}

1. CANABRAVA, Alice. O comércio português no Rio da Prata; 1580-1640. 2.ed. Belo Horizonte, Itatiaia/USP, 1984; CESAR, Guilhermino. O contrabando no sul do Brasil. Caxias do Sul, UCS: Porto Alegre, Escola Superior đe Teologia São Lourenço de Brindes, 1978. (Col. Temas Gaúchos)

2. Parágrafo III. Reais providências. Descrição corográfica, política, civil e militar da capitania do Rio Grande de São Pedro do Sul. Revista Resquisas. História, Porto Alegre, Instituto Anchietano de Pesquisas, 15, 1961. p.88.

3. CESAR, Guilhermino, Primeiros cronistas do Rio Grande do Sul; 1605-1801. 2.ed. Porto Alegre, ERUS, 1981. p.129.

4. Reverbel, Carlos. Roteiro bibliográfico. Notas avulsas. Correio do Povo, supl. Porto Alegre, 3 set. 1955. p.9.

5. Ibidem.

6. Saint-Hilaire, Auguste de. Viagem ao Rio Grande do Sul (1820-1821). São Paulo, Ed. da USP; Belo Horizonte, Itatiaia, 1974. (Reconquista do Brasil, 10)

7. Ibidem, p.119.

8. Ibidem, p.177.

9. Saint-Hilaire, op. cit., p.46. 
10. Ibidem.

11. Saint-Hilaire, op. cit., p.168.

12. Ibidem, p.191

13. Ibidem.

14. Saint-Hilaire, op. cit., p.199.

15. Ibidem, p. 164 .

16. Ibidem, p.108-9.

17. Ibidem, p.196.

18. Ibidem.

19. Saint-Hilaire, op. cit., p.65.

20. Ibidem, p.73.

21. Ibidem, p.80.

22. Ibidem, p.204

23. Ibidem, p.47.

24. Ibidem, p.186.

25. Ibidem, p.80.

26. Ibidem, p. 187 e 190.

27. Ibidem, p.31.

28. Saint-Hilaire, op. cit., p.,32.

29. Ibidem, p.47

30. Ibidem, p.73.

31, Ibidem, p.47.

32. Vellinho, Moysés. Aparas do tempo. Porto Alegre, ERUS, 1981. p.81-94.

33. Ibidem, p.89.

34. Ibidem.

35. Ibidem, p. 93 .

36. Vellinho, Moysés. Aparas [...]. p.127-39.

37. Ibidem, p.130.

38. Ibidem, p.131.

39. Ibidem, p.136.

40. Vellinho, Moysés. A configuração atual do Rio Grande e sua fronteira histórica. Fundamentos da Cultura Rio-grandense, $5^{\mathrm{a}}$ série. Porto Alegre, Gráfica da UFRGS, 1960. p.179-90.

41. Vellinho, Moysés. Capitania d'El Rei: Aspectos polêmicos da formação rio-grandense. Porto Alegre, Globo, 1970. (Col. Província) [1.ed. 1964]

42 Vellinho, Moisés. Fronteira. Porto Alegre, Globo, 1975. (Col. Província)

3. Vellinho, Moysés. Os jesuítas no Rio Grande do Sul. Fundamentos da Cultura Rio-grandense, $4^{2}$ série. Porto Alegre, Gráfica da UFRGS, 1960. p.110.

44. Vellinho, Moysés. Capitania [...]. p.72.

45. Vellinho, Moysés. Conquista e povoamento no Rio Grande do Sul. Boletim do Gabinete Português de Leitura.. Número comemorativo ao Biênio da Colonizaçăo e Imigração. Porto Alegre, A Nação, 23:15-21, 1974. p.15.

46. Ibidem, p.16.

47. Ibidem.

48. Ibidem.

49. Vellinho, Conquista e povoamento [...]. p.16.

50. Vellinho, Moysés. Capitania [...]. p.146.

51. Ibidem, p.2-3.

52. Abreu, Florêncio de. Aspectos do desenvolvimento econômico e financeiro do Rio Grande do Sul, em comemoraçóes em honra ao Centenário de Independência do Brasil. Porto Alegre, A Federação, 1922. p.26; LAYTANO, Dante de. O negro no Rio Grande do Sul. Porto Alegre, Publicação de Comissão Gaúcha do Folclore, Tip. Champagnat, 1958. 
53. Vellinho, Capitania [...]. p.216.

54. Vellinho, Moysés. Editorial. Revista Província de São Pedro, Porto Alegre, 21:5-10, 1957.

55. Vellinho, Moysés. Letras da Província. Porto Alegre, Globo, 1944. p.130.

56. Vellinho, Moysés. Antecedentes da formação histórica do Rio Grande do Sul. Revista Província de São Pedro, Porto Alegre, 21:195-208, 1957

57. Vellinho, Conquista e povoamento...

58. Vellinho, Capitania [...], p.106.

59. Ibidem, p.129. 